\title{
BUSINESS CYCLES SYNCHRONISATION BETWEEN THE EU-15 AND SELECTED EASTERN EUROPEAN COUNTRIES - THE WAVELET COHERENCE APPROACH
}

\author{
Jovan NJEGIĆ - Dejan ŽIVKOV - Jelena DAMNJANOVIĆ \\ (Received: 7 January 2017; revision received: 5 June 2017; accepted: 13 July 2017)
}

This paper strives to investigate the level of business cycles synchronisation between 8 Central and Eastern European Countries (CEEC) and the EU-15. We use wavelet coherence and phase difference methodology as a very suitable tool that observes simultaneously the strength of business cycles' co-movement in the aspect of time as well as in the aspect of frequency. The results indicate that the business cycles of CEECs are generally synchronised with the EU-15 business cycles, whereas distinct differences existed before, during, and after the financial crisis (2008-2009) and during the European sovereign debt crisis (2010-2011). In other words, we demonstrate that very strong business cycles synchronisation occurred in almost all CEECs during crisis periods and at higher wavelet scales, while only moderate synchronisation is recorded in relatively tranquil periods at higher frequencies. The results suggest that smaller CEECs, but also larger countries such as the Czech Republic, Hungary, and to some extent Slovakia as well have a higher level of business cycles synchronisation with the EU-15, particularly in the crisis period at short-run as well as at long-run fluctuations. However, we do not find strong business cycles co-movement in cases of Poland and Latvia via HP and BP filters at higher frequencies during the crisis, which might indicate a higher resistance of these countries to external systemic shocks.

Keywords: wavelet coherence, business cycles, Central and Eastern European countries

JEL classification indices: C63, E30, E32

Jovan Njegić, Professor at Novi Sad School of Business, University of Novi Sad, Serbia. E-mail: jovan.nj@gmail.com

Dejan Živkov, corresponding author. Lecturer at Novi Sad School of Business, University of Novi Sad, Serbia, E-mail: dejanzivkov@gmail.com

Jelena Damnjanović, Professor at Novi Sad School of Business, University of Novi Sad, Serbia. E-mail: jdamnjanovic5@gmail.com 


\section{INTRODUCTION}

The European idea of greater economic integration got a new concept on May 1, 2004, when 8 former centrally planned economies from Central and Eastern Europe (CEECs) - the Czech Republic, Poland, Hungary, Slovakia, Slovenia, Lithuania, Latvia, and Estonia - became members of the European Union (EU). Subsequently, some of these countries also became members of the European Monetary Union (EMU), namely Slovakia (January 1, 2009), Estonia (January 1, 2011), Latvia (January 1, 2014), and Lithuania (January 1, 2015). There are plans for the Czech Republic, Poland, and Hungary also joining the EMU.

Mundell (1961) pioneered the idea of Optimal Currency Area (OCA), claiming that the costs of joining OCA can be higher than benefits if economic convergence requirements are not met. Some of these requirements such as high degree of external openness, greater mobility of production factors (labour and capital), and diversified production structures should increase the level of business cycles synchronisation. Artis et al. (2008) also contributed to this opinion. They analysed the potential sources of business cycles synchronisation and its changes over time, and found that countries with large bilateral trade and financial flows tend to have more correlated business cycles. Thus, a higher probability of having symmetric economic shocks reduces conflicts across member countries regarding the preferred monetary policy. Frankel - Rose (1998) advocated the idea of the endogeneity of the OCA, namely that countries that do not fulfil the OCA criteria before entering the monetary union could satisfy them upon entering. Business cycles synchronisation is not a sufficient guarantee that the monetary union will be successful. In OCA member states with asynchronous business cycles, a common monetary policy could be ineffective or even harmful.

Most of the literature on this topic considers business cycles synchronisation using only the time aspect, but this approach neglects the frequency characteristic that exists in financial time series (e.g., Aguiar-Conraria et al. 2008). Berdiev Chang (2015) explained that the synchronisation of growth cycles may be high at long-run developments, whereas there may be a low degree of co-movement at short-run fluctuations for a particular sample period. Moreover, Herrerias - Ordonez (2014) asserted that a common linear approach underestimates the strength of business cycles synchronisation between countries, attaching much weight to sharp movements during various phases of peaks and troughs. Fidrmuc - Korhonen (2010) argued that growth cycles may exert significant oscillations across various frequencies, as different economic policies may cause divergence between business cycles.

Our paper analyses the level of business cycles synchronisation between the EU-15 and the 8 Eastern European economies. Firstly, we segregate the cycli- 
cal component from the deseasonalised real GDP growth by using two different non-parametric filters - the Hodrick-Prescott filter (HP, 1997) and the band-pass (BP) filter proposed by Baxter - King (1999). ${ }^{1}$ Secondly, in order to broaden our analysis beyond the simple time aspect, we employ the wavelet-based measure of co-movement, i.e. the wavelet squared coherence proposed by Croux et al. (2001). This is a powerful signal processing tool that provides a more comprehensive analysis of business cycles synchronisation. In other words, it stretches into a long wavelet function to measure low-frequency movements and it compresses into a short wavelet function to measure high-frequency movements. ${ }^{2}$ To the best of our knowledge, very few studies have utilised the wavelet coherence approach for the study of business cycles synchronisation, one of these being Aguiar-Conraria - Soares (2011) investigated business cycles links which between some CEECs and the EU-15. We contribute to the existing literature in several ways. We include more CEECs in the analysis in comparison to the study just mentioned. Our paper covers two recent financial crises - the international financial crisis (IFC) and the European sovereign debt crisis (ESDC), and wavelet coherence is done on the cyclical components derived from the two different non-parametric filters, HP and BP.

The rest of the paper is structured as follows: Section 2 presents an overview of the related literature and similar studies. The theoretical underpinning of continuous wavelet transformation (CWT), wavelet coherence, and wavelet phase difference is given in Section 3. Section 4 contains the data-frame and descriptive statistics of created business cycles via the HP and BP filters. Section 5 presents the wavelet coherence plots and discusses the results, and Section 6 concludes.

\section{LITERATURE REVIEW AND RELATED STUDIES}

There is a significant body of literature regarding business cycles synchronisation that is related to the optimal currency areas (OCA) as well as to the analysis of the countries and regions that have attempted to promote greater trade and economic integration (see, e.g., Stock - Watson 2005; Harding - Pagan 2006; Canova et al. 2007; Inklaar et al. 2008; de Haan et al. 2008; Quah - Crowley 2010; Xie et al. 2013; Allegret - Essaadi 2011; Cerqueira - Martins 2009; Gong - Kim 2013; Furceri - Karras 2008; Quah 2014).

1 The same filters were applied by Degiannakis et al. (2014) and Obradović - Mihajlović (2013) for robustness check purpose.

2 Our study was inspired by the papers of Yogo (2008), Aguiar-Conraria - Soares (2011), and Berdiev - Chang (2015). 
As for the CEECs, the international community has shown a special interest in this topic in the past 10-15 years since trade and financial transactions between these countries and Western Europe have increased. For instance, Valentinaite Snieška (2005) demonstrated that the demand and supply shocks between Lithuania, Latvia, Estonia, and Poland are in most cases highly positively correlated, but demand shock correlation is lower on average than supply shock correlation. Kutan - Yigit (2004) reported an increasing synchronisation between the CEECs and the euro zone. Aslanidis (2010) gauged the business cycles synchronisation between the three largest CEECs and the euro zone. His findings led to the conclusion that Hungary is highly synchronised with the euro zone, while Poland and the Czech Republic show a lower degree of synchronisation. Fidrmuc - Korhonen (2006) found similar results, claiming that these three countries achieved a relatively high degree of synchronisation with the euro zone, while other countries did not. Darvas - Szapáry (2008) assessed business cycles synchronisation by computing cross-correlation matrices via the SVAR model between the EMU and the CEECs. Their results showed an increase in the cyclical correlation during the whole sample period in Hungary, Poland, and Slovenia from 1993 to 2002, while the other five CEECs displayed a low synchronisation during the same period. The study of Eickmeier - Breitung (2006) analysed the degree of cyclical synchronisation between the new EU member states from Central and Eastern Europe, concluding that Hungary, Estonia, Slovenia, and Poland are more suitable accession candidates for the EMU in comparison to the other new member states. They also asserted that Hungary and Estonia are deeply integrated in terms of trade and FDI, and that they exhibit industry structures that are similar to those in the euro zone. They found that the Slovenian economy is closely connected through trade with the euro zone, whereas Lithuanian output growth correlation with the euro zone is very low.

Savva et al. (2010) considered a bivariate VAR-GARCH model with timevarying correlations to test the business cycles correlations between the EMU aggregate cyclical industrial production and each of the new and negotiating member countries. Conducting the research on the sample from 1980, they showed that the highest correlations with the euro zone were recorded in Hungary (0.68), Slovenia (0.54), the Czech Republic (0.50), Poland (0.49), and Estonia (0.48). Hegerty (2010) indicated that the relative synchronisation of co-movements of the six CEE countries with Germany is not higher than the correlation of the CEE countries' business cycle with the world business cycle. On the other hand, Stanisic (2013) examined the co-movements between CEECs' GDP and the 16 members of euro zone by applying a double HP filter method to the series and evaluating the degree of the co-movement of cycles on the basis of various methods of rolling correlations. His results revealed that there is no common CEEC 
business cycle, although there is a synchronisation trend over time. Di Giorgio (2016) investigated the possible business cycle linkages between CEECs that were candidates to enter the EMU for the period 1993 to 2014 by using Markov switching autoregressive models and synchronisation tests. He found that the business cycles synchronisation is quite high in the recession regime, but lower in the normal and high growth regimes, with the exception of Hungary and Poland. Chionis - Leon (2009) examined the synchronisation between the European and the Polish business cycles via VAR methodology. Their findings confirmed that while business cycles are dominated by the same frequency, there is a time lag between these two cycles. Therefore, they concluded that compared to the benefits, the costs of participation in the monetary union are not negligible. Applying a multi-factor model, Jiménez-Rodríguez et al. (2013) investigated the degree of co-movements in real macroeconomic aggregates across the selected euro zone and the CEECs. They reported that the evolution of the global European factor matches well the narrative of main economic events between 1995 and 2011 as

Table 1. Summary of studies that investigated business cycles synchronisation in CEEC

\begin{tabular}{|c|c|c|c|c|}
\hline Author(s) & Data sample & Frequency & Methodology & Analysed CEECs \\
\hline $\begin{array}{l}\text { Valentinaitè - } \\
\text { Snieška (2005) }\end{array}$ & 1993:4-2003:4 & Quarterly & Structural VAR & EE, LV, LT \\
\hline Kutan - Yigit (2004) & 1993:1-2000:12 & Monthly & $\begin{array}{l}\text { Panel estimation } \\
\text { approach }\end{array}$ & $\begin{array}{l}\text { CZ, HU, PL, SK, } \\
\text { SL, RO, LV, LT, EE, } \\
\text { BG }\end{array}$ \\
\hline Aslanidis (2010) & 1993:2-2006:4 & Monthly & Threshold SUR & $\mathrm{CZ}, \mathrm{HU}, \mathrm{PL}$ \\
\hline $\begin{array}{l}\text { Fidrmuc - Korhonen } \\
\text { (2006) }\end{array}$ & $1998-2005$ & $\begin{array}{l}\text { Quarterly, } \\
\text { monthly }\end{array}$ & $\begin{array}{l}\text { Meta-regression } \\
\text { analysis }\end{array}$ & $\begin{array}{l}\text { CZ, HU, PL, SK, } \\
\text { SL, EE, LV, LT, BG, } \\
\text { RO }\end{array}$ \\
\hline $\begin{array}{l}\text { Darvas - Szapáry } \\
(2008)\end{array}$ & 1983:1-2002:4 & Quarterly & \begin{tabular}{|l|}
$\begin{array}{l}\text { Five different } \\
\text { measures }\end{array}$ \\
\end{tabular} & $\begin{array}{l}\text { CZ, HU, PL, SK, } \\
\text { SL, LV, LT, EE } \\
\end{array}$ \\
\hline $\begin{array}{l}\text { Eickmeier - Breitung } \\
(2006)\end{array}$ & 1993:1-2003:4 & Quarterly & Structural VAR & $\begin{array}{l}\text { CZ, HU, PL, SK, } \\
\text { SL, LV, LT, EE } \\
\end{array}$ \\
\hline Savva et al. (2010) & 1980:1-2006:6 & Monthly & \begin{tabular}{|l} 
Bivariate \\
VAR-GARCH
\end{tabular} & $\begin{array}{l}\text { CY, CZ, EE, HU, } \\
\text { LT, PL, RO, SK, SL }\end{array}$ \\
\hline Hegerty (2010) & 1993:1-2008:4 & Quarterly & Cross correlation & $\begin{array}{l}\text { CZ, HU, PL, LV, } \\
\text { LT, EE }\end{array}$ \\
\hline Stanisic (2013) & 1995:1-2012:1 & Quarterly & Correlation matrix & $\begin{array}{l}\mathrm{CZ}, \mathrm{HU}, \mathrm{PL}, \mathrm{SK}, \\
\text { SL, EE, LV, LT, BG, } \\
\text { RO }\end{array}$ \\
\hline di Giorgio (2016) & 1993:1-2014:4 & Quarterly & MS-VAR & $\begin{array}{l}\text { CZ, HU, PL, RO, } \\
\text { BG, LV, LT } \\
\end{array}$ \\
\hline $\begin{array}{l}\text { Chionis - Leon } \\
(2009)\end{array}$ & 1995:1-2006:1 & Quarterly & $\begin{array}{l}\text { Spectral and VAR } \\
\text { method }\end{array}$ & PL \\
\hline $\begin{array}{l}\text { Jiménez-Rodríguez } \\
\text { et al. (2013) }\end{array}$ & 1995:2-2011:4 & Quarterly & MS-VAR & CZ, HU, PL, SK, SL \\
\hline
\end{tabular}


well as a high degree of concordance between country-specific and European business cycles. Table 1 offers an overview of the studies that investigated business cycles synchronisation in CEECs.

\section{CONTINUOUS WAVELET TRANSFORM, WAVELET COHERENCE, AND WAVELET PHASE DIFFERENCE}

Wavelet methodology presents the estimation of the spectral characteristics of a time-series as a function of time, disclosing how the different periodic components of a particular time-series evolve over time. According to Rua - Nunes (2009), the continuous wavelet transform $W_{x}(u, s)$ is obtained by projecting a specific wavelet $\psi\left(\right.$.) onto the examined time series $x(t) \in L^{2}(\mathbb{R})$ by the following expression:

$$
W_{x}(u, s)=\int_{-\infty}^{\infty} x(t) \frac{1}{\sqrt{s}} \bar{\psi}\left(\frac{t-u}{s}\right) d t
$$

where $u$ represents the position of the wavelet in the time aspect, while $s$ stands for the position in the frequency aspect. As a result, the information on time and frequency can be simultaneously obtained by mapping the original time series into the function of $u$ and $s$ in the wavelet transform. Furthermore, the CWT has an important feature to decompose and then subsequently perfectly reconstruct the time series $x(t) \in L^{2}(\mathbb{R})$ according to the following equation:

$$
x(t)=\frac{1}{C_{\psi}} \int_{0}^{\infty}\left[\int_{-\infty}^{\infty} W_{x}(u, s) \psi_{u, s}(t) d u\right] \frac{d s}{s^{2}}, s>0 .
$$

Moreover, the CWT preserves the energy of the examined time series, i.e. it does not waste valuable information.

$$
\|x\|^{2}=\frac{1}{C_{\psi}} \int_{0}^{\infty}\left[\int_{-\infty}^{\infty}\left|W_{x}(u, s)\right|^{2} d u\right] \frac{d s}{s^{2}}
$$

Bivariate framework called wavelet coherency and wavelet phase-difference are the concepts of cross wavelet power. They represent natural generalisations of the basic wavelet analysis tools and they underline the time-frequency dependencies between the two time-series. Particularly, CWT should be applied to investigate the interaction between the two time-series, in order to explain how closely X and Y are related by a linear transformation (see Rahim - Masih 2016). According to Vacha - Barunik (2012), the squared wavelet coherence measures the local linear correlation between two stationary time series at each scale, and it is equivalent to the squared correlation coefficient in linear regression. Referring 
to Torrence - Webster (1999), CWT is defined as the squared absolute value of the smoothed cross wavelet spectra normalised by the product of the smoothed individual wavelet power spectra of each selected time series. The cross wavelet transform of the two time-series, $x(t)$ and $y(t)$, is defined as $W_{x y}(u, s)=W_{x}(u, s)$ $\bar{W}_{y}(u, s)$, where $W_{x}$ and $W_{y}$ are the wavelet transforms of $x$ and $y$, respectively. The squared wavelet coherence coefficient is given as follows:

$$
R^{2}(u, s) \frac{\left|S\left(s^{-1} W_{x y}(u, s)\right)\right|^{2}}{S\left(s^{-1}\left|W_{x}(u, s)\right|^{2}\right) S\left(s^{-1}\left|W_{y}(u, s)\right|^{2}\right)}
$$

where $S($.$) stands for a smoothing operator and s$ is a wavelet scale. The squared wavelet coherence coefficient ranges $0 \leq R^{2}(u, s) \leq 1$, where values near zero point to weak correlation, while values near one indicate strong correlation. CWT is estimated utilising Monte Carlo simulation methods.

The CWT approach is unable to determine whether dependence is positive or negative because the wavelet coherence is squared. Thus, we also consider wavelet coherence phase differences, which delineate details about the delays in the oscillation (cycles) between the two time-series under study. With reference to Torrence - Webster (1999), the wavelet coherence phase difference is defined as follows:

$$
\phi_{x y}(u, s)=\tan ^{-1}\left(\frac{\mathfrak{I}\left\{S\left(s^{-1} W_{x y}(u, s)\right)\right\}}{\mathfrak{R}\left\{S\left(s^{-1} W_{x y}(u, s)\right)\right\}}\right) .
$$

The phase difference between the two series $(\mathrm{x}, \mathrm{y})$ is indicated by arrows on the wavelet coherence plots. As Vacha - Barunik (2012) asserted, right (left) pointing arrows indicate that the time series are in-phase (anti-phase) or are positively (negatively) correlated. If arrows point to the right and upward, the second variable is lagging, and if they point to the right and downward, the second variable is leading. Conversely, if arrows point to the left and upward, the second variable is leading, and if arrows point to the left and downward, the second variable is lagging.

\section{THE DATASET AND THE PRELIMINARY ANALYSIS}

Our dataset comprises seasonally adjusted real GDP figures of 8 CEEC countries (Table 2) and 15 old EU Member States (EU-15). The period covered ranges from Q2 1995 to Q3 2016. Our source was the OECD. In order to enhance the robustness of the results, the study uses two methods of data detrending (separation of 
the trend from the cyclical component): the Hodrick-Prescott filter (HP, 1997) and the band-pass (BP) filter proposed by Baxter - King (1999).

Applying the HP filter to quarterly data, we adjust the smoothness parameter $(\lambda)$ with the value of 1600 . On the other hand, the BP filter is different from the HP filter in the sense that this filter removes from the time series those fluctuations that have frequencies that are too high or too low. In order to avoid too much filtering of high frequency movements, we use the lower threshold value of 2 , and the upper of 32. In this manner, the filter removes trend variation and all the oscillations that last less than 2 quarters (half year) and more than 32 quarters ( 8 years), and includes the oscillations that range from 0.5 to 8 years. In financial literature, it is called "high pass" filter. In that sense, BP business cycles structure seems similar to the cycles that are obtained by HP filter, i.e. both HP and BP business cycles have rather rigid and serrated peaks and troughs, as can be seen on the plots of Figure 1. Regarding the length of our GDP series, and according to Baxter and King (1999), we detrend real GDP by applying four moving average (MA) components of real GDP series. However, one shortcoming of the BP approximation procedure is that some amount of data has to be "discarded" at the beginning and at the end of the sample period because moving average smoothing process has to be employed. Since we employ four quarter moving averages, we lose eight quarters of the empirical data.

Table 2. Descriptive statistics of HP-filtered and BP-filtered real GDP

\begin{tabular}{l|c|c|c|c|c|c|c|c}
\hline & \multicolumn{4}{|c}{ HP business cycles } & \multicolumn{4}{c}{ BP business cycles } \\
\hline & St. dev. & Min. & Max. & No. obs. & St. dev. & Min. & Max & No. obs. \\
\hline EU-15 & 0.484 & -2.667 & 0.971 & 86 & 0.398 & -2.167 & 0.706 & 78 \\
\hline CZH & 0.786 & -4.004 & 2.268 & 86 & 0.559 & -3.321 & 1.037 & 78 \\
\hline POL & 0.991 & -4.714 & 4.656 & 86 & 0.989 & -4.731 & 4.554 & 78 \\
\hline HUN & 0.759 & -3.767 & 0.987 & 86 & 0.725 & -3.219 & 1.409 & 78 \\
\hline SLK & 1.644 & -9.947 & 6.688 & 86 & 1.635 & -8.865 & 7.217 & 78 \\
\hline SLO & 0.983 & -4.462 & 2.643 & 86 & 0.890 & -3.651 & 2.517 & 78 \\
\hline LIT & 1.858 & -13.195 & 2.970 & 86 & 1.665 & -11.283 & 2.836 & 78 \\
\hline LAT & 1.780 & -5.752 & 4.061 & 86 & 1.449 & -3.609 & 3.601 & 78 \\
\hline EST & 1.897 & -8.978 & 2.988 & 86 & 1.604 & -6.899 & 4.418 & 78 \\
\hline
\end{tabular}

Source: Authors' calculations.

Table 2 illustrates summary statistics for business cycles obtained by HP and BP filters. The mean values are omitted, since all cycles oscillate around zero. In addition, it can be seen that all standard deviations, minimums and maximums are very similar (both with HP and BP), but BP standard deviations are lower in comparison to the HP counterparts. According to HP and BP filters, the Baltic 

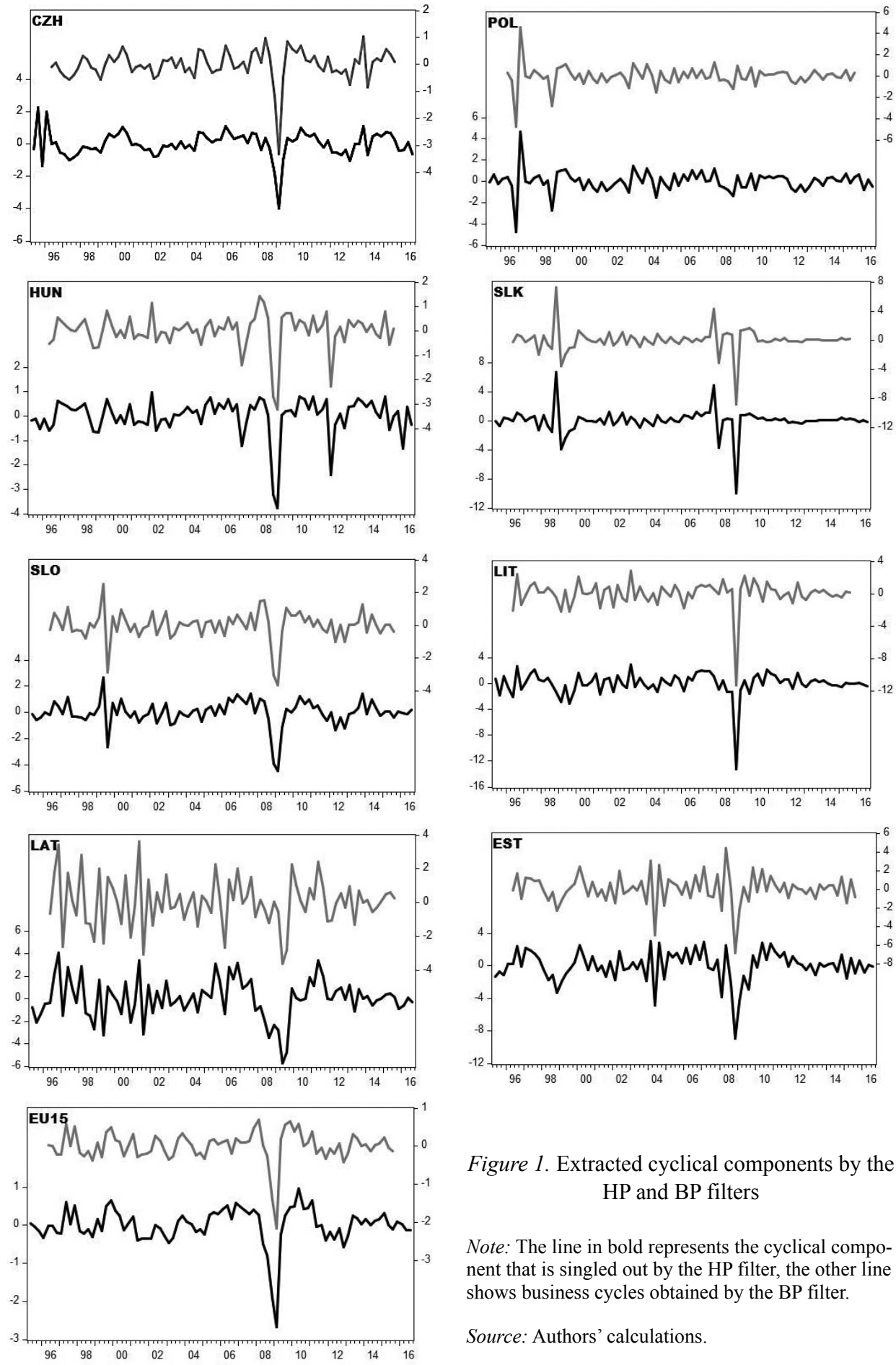

Figure 1. Extracted cyclical components by the HP and BP filters

Note: The line in bold represents the cyclical component that is singled out by the HP filter, the other line shows business cycles obtained by the BP filter.

Source: Authors' calculations. 
countries and Slovakia reported the highest oscillations, while Hungary has the lowest volatility rate of business cycles of all CEECs. Comparatively speaking, the EU-15 group has the most equable dynamics of the real GDP. This assertion is further verified by the lowest minimum and maximum values of the EU-15 real GDP. Lithuania had the lowest drop of its quarterly real GDP during the international financial crisis $(\mathrm{HP}=-13.195$ and $\mathrm{BP}=-11.283)$, while Slovakia recorded the highest peak in the time of prosperity $(\mathrm{HP}=6.688$ and $\mathrm{BP}=7.217)$.

Table 3 discloses the results of the unconditional Pearson correlation coefficients between the business cycles of selected countries that are obtained by the HP and BP filters. As can be seen, all correlation coefficients between the HP cycles of CEECs and EU-15 are statistically significant, but their values are heterogeneous. Table 3 also suggests that almost all correlation coefficients between BP business cycles are slightly smaller, but at the same time very similar with the HP counterparts, while only in cases of Poland and Latvia, these coefficients are statistically insignificant. These findings are in line with the results of Obradović - Mihajlović (2013), who also compared these two methods of business cycles filtration.

Table 3. Pearson's correlation for HP and BP business cycles between EU-15 and CEECs

\begin{tabular}{l|c|c|c|c|c|c|c|c}
\hline & CZH & POL & HUN & SLK & SLO & LIT & LAT & EST \\
\hline HP filter & $0.609^{* * *}$ & $0.223^{* *}$ & $0.652^{* * *}$ & $0.324^{* * *}$ & $0.671^{* * *}$ & $0.598^{* * *}$ & $0.332^{* * *}$ & $0.531^{* * *}$ \\
\hline BP filter & $0.611^{* * *}$ & 0.113 & $0.634^{* * *}$ & $0.321^{* * *}$ & $0.559^{* * *}$ & $0.555^{* * *}$ & 0.082 & $0.386^{* * *}$ \\
\hline
\end{tabular}

Note: $* * *, * * *$ indicate statistical significance at the $10 \%, 5 \%$, and $1 \%$ level, respectively. The results without asterisks are statistically insignificant.

Source: Authors' calculations.

According to the HP filter, the country that is most synchronised with the EU-15 is Slovenia, followed by Hungary, the Czech Republic, and Lithuania. In contrast, Poland has the least synchronised business cycles with the EU-15 pursuant to HP filter. On the other hand, Hungary is the most synchronised country with the EU-15 according to BP filter, while the Czech Republic, Slovenia, and Lithuania follow. Pearson's unconditional correlation offers limited information about the dynamics of business cycles synchronisation because it calculates only average static coefficients and neglects the time aspect as well as the frequency dimension characteristics. Therefore, in the following section, we present the wavelet coherence results, a methodology that overcomes all the deficiencies of static correlation presentation. 


\section{THE WAVELET COHERENCE RESULTS}

In order to investigate the level of business cycles synchronisation between the selected CEECs and EU-15 through time and through scales, we have plotted CWT results, which can be seen in Figure 2. These images contain three dimensions. Firstly, the strength of the mutual co-movement between the cycles is depicted on the contour plot, where dark-grey areas of the wavelet-based measure represent strong interdependence, while light-grey areas indicate low interconnection. In other words, regions of high coherency between the two countries are synonymous of strong local correlation. The cone of influence indicates that a wavelet-based measure of co-movement between the growth cycles of country pairs for a particular time and frequency aspect are statistically significant at the $5 \%$ level. Secondly, mutual interdependence can be observed over time, whereby the horizontal axis represents the time period of the analysis (Q2:1995-Q3:2016). Thirdly, the left vertical axis denotes the frequency, expressed in quarterly time units, i.e. one can observe how business cycles were synchronised in different time periods. In particular, we set the frequency to range from 2 to 16 quarters, i.e. four years, which is similar to what Berdiev - Chang (2015) did.

Figure 2 presents the results of CWT between the EU-15 and CEECs business cycles that were obtained by the HP and BP filters. It is obvious that a broadly consistent pattern emerges in all wavelet coherence plots. Figure 2 indicates that the business cycles of CEECs are synchronised with EU-15 business cycles in general, but the strength of business cycles synchronisation fluctuates significantly across frequencies and over time, regarding different pairs of countries. As can be seen, all CEECs report very strong synchronisation at low frequencies (long-term developments), while up to four-quarters light-grey colours prevail, which is an indication of moderate business cycles' co-movement. This may result from the fact that very short-term fluctuations are essentially idiosyncratic, as Rua (2010) contended. These findings are not distinctively different from CWTs calculated with HP and BP business cycles, which favour the results' robustness.

Moreover, it is interesting to note that distinct differences exist during the various time-periods, i.e. before, during, and after the WFC (2008-2009) and ESDC (2010-2011) in all CWT plots. The analysis of business cycles co-movement in periods of extreme market disturbance contributes to the better comprehension of how well business cycles are synchronised. Generally, the results of HP and BP plots are very consistent, without any serious discrepancies between HP and BP plots. As can be seen in almost all CWT plots, very strong business cycles synchronisation occurred during the crisis periods. Our findings coincide with the results of di Giorgio (2016) who analysed the same CEECs as we did and asserted that these countries share the same business cycle features when they 
are in a recession regime, but that is less evident when they are in an economic expansion phase. White lines in all CWT plots outline the areas of very strong (over 95\%) co-movement between business cycles. Unlike the tranquil periods, strong wavelet coherence is visible at both low frequencies and high frequencies during the crisis, which cannot be attributed to idiosyncratic, but rather to contagion factors.

In order to highlight the regions of high coherency, we plot phase-difference arrows only in white delineated islands. The majority of black arrows point in straight right or upper right directions. The former suggests that business cycles are in phase, while the latter contains the information about the lead/lag relationship between the business cycles of CEECs and the EU-15. As we have said earlier, if phase arrows point to the right and upward, the second variable is lagging, i.e. CEECs. Being in phase means that business cycles move simultaneously in the same direction. In contrast, in the light-grey areas, the arrows point in all directions, ${ }^{3}$ indicating that idiosyncratic (country-specific) factors of the business cycles are dominant at high frequencies. These characteristics are inherent to all CEECs. Regarding the lead/lag relationship, it can be concluded that the business cycles of CEECs follow the economic cycle-developments of the EU-15, which is concluded from the fact that in some cases and at higher scales, the arrows point upwards, e.g. the cases of the Czech Republic, Hungary, Slovakia, Lithuania, and Latvia. Only in few instances, the arrows point downwards in the righthand direction, which indicates that some particular CEECs begin business cycle conjecture before the EU-15. For example, this specific occurrence can be noted in the EU-15 vs. Hungary plots, where at high frequencies (up to fourth scale) and during the WFC, the arrows point downwards, indicating that the Hungarian economy started to sink into recession before the WFC struck the EU-15 group. This can be noticed in both HP and BP plots. On the other hand, high coherency islands between the fourth and eighth scales with arrows pointing downwards are recorded during the tranquil period around 2004 in the HP and BP plots of the EU-15 vs. Poland. This period was characterised by an overall economic boost in Europe, and CWT plots indicate that Poland commenced the positive business cycle phase before the EU-15. An anti-phase situation occurs very rarely: we find arrows pointed to straight-left at the fourth scale between 2008 and 2010 only in case of Latvia. This indicates that Latvian business cycles were moving in opposite direction compared to EU-15 business cycles in that particular period.

The case of Poland should be analysed in greater detail because Poland is the largest CEEC that had a very modest wavelet coherency with the EU-15 during the WFC and ESDC at all scales in the HP plot, which is different in comparison

These plots are not presented, but are available upon request. 

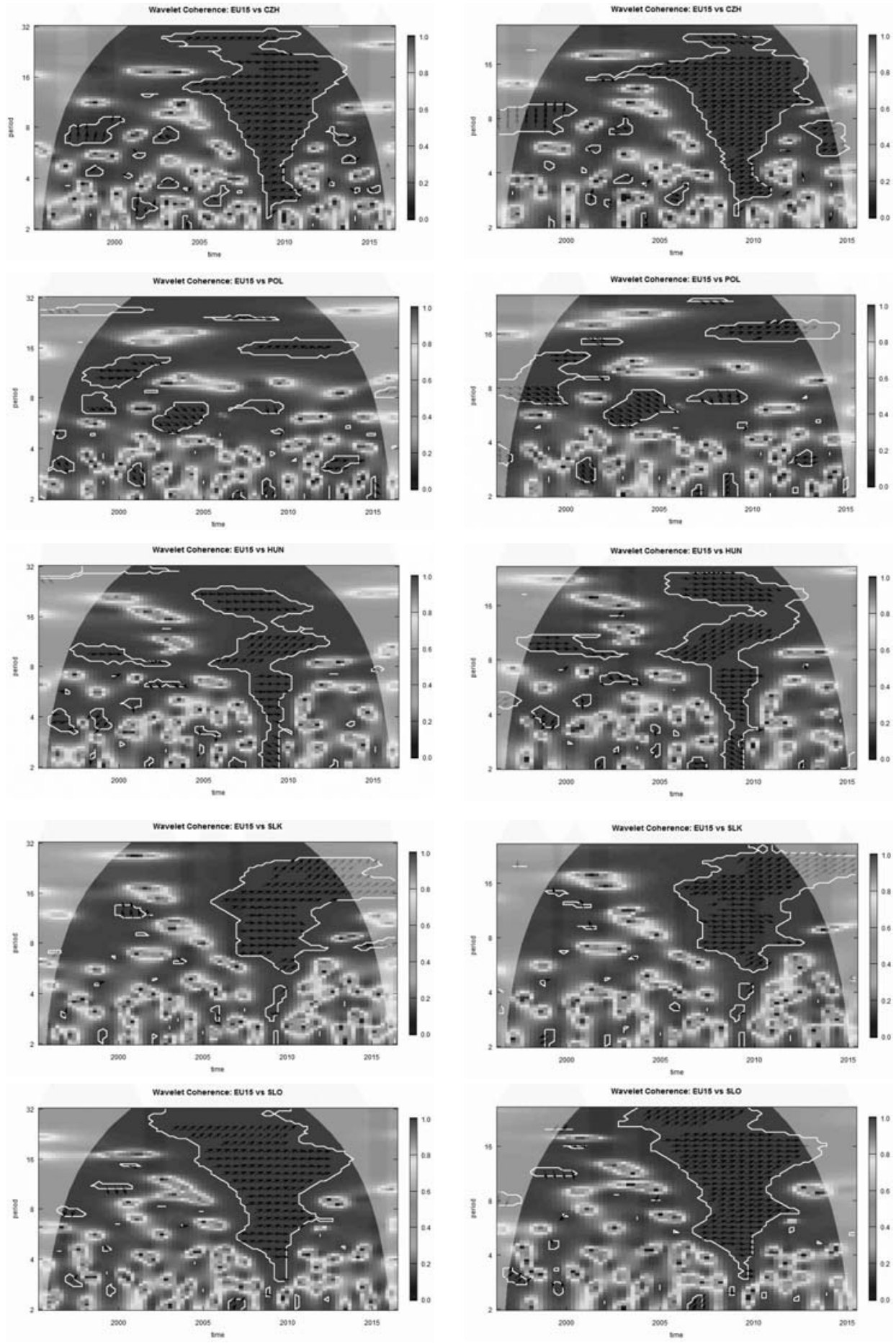

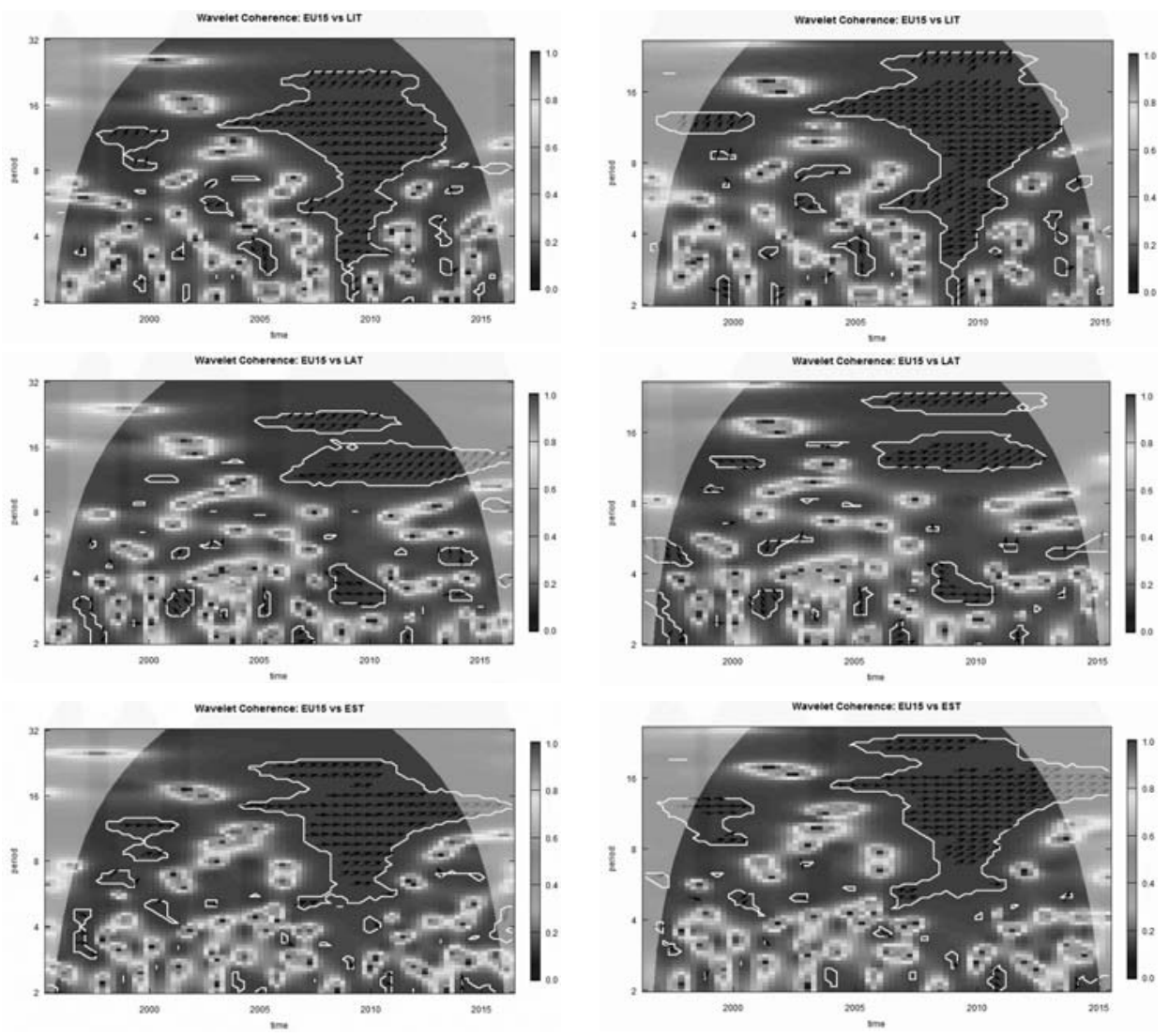

Figure 2. Results of the wavelet coherence between the EU-15 and the CEECs business cycles

Note: The left-hand (right-hand) side plots present CWT images calculated with HP (BP) cycles.

Source: Authors' calculations.

to the other large CEECs. This might be an indication that Poland has a lower level of integration in the EU compared to other major CEECs, and thus a lower level of business cycles synchronisation. This finding is expected to a certain extent since Poland is the largest CEE economy and we can hardly expect that its cycles can accommodate the movements of the core Europe as well and as fast as some of the much smaller CEECs. The preliminary Pearson's coefficient of correlation also indicates lower co-movement with the EU-15, which is similar to the findings of Aslanidis (2010). He contended that the Czech Republic and Poland in particular have less synchronised business cycles in comparison to Hungary. However, these characteristics of the Polish economy have their good 
points since it also means that the level of resistance is higher and that Poland has a better ability to cushion external systemic shocks. Chionis - Leon (2009) argued that the Polish cycles significantly lag behind the European cycles and they based their contention on the VAR methodology results, which showed that the shocks from the European markets were absorbed within six to ten quarters. Somewhat similar findings can be seen on our CWT plot.

On the other hand, the Czech Republic, Hungary, Slovakia, Slovenia, Lithuania, and Estonia appear to have much more synchronised cycles with the EU-15, as both HP and BP plots suggest. For instance, Jiménez-Rodríguez et al. (2013) found that Hungary and Slovenia behave similarly to the EMU-8, where the global European factor accounts, on average, for around 53\% of output volatility, and the idiosyncratic component represents, on average, about $40 \%$. Apart from Hungary and Slovenia, we find very strong wavelet coherence for Lithuania during the crisis at high frequencies and for Estonia at lower frequencies (from the 4 th scale and upper). The reason could lie in the fact that these countries are relatively small and thus more sensitive to external shocks, but the reasons could also lie in enhanced trade and financial linkages that these countries have strengthened since they joined EU. In contrast, Latvia demonstrates a pattern similar to Poland, i.e. we find very limited high coherency areas during the crisis, and it happened at very low frequencies. In addition, both HP and BP CWT results show an even anti-phase position during the crisis at relatively high frequencies (around the fourth scale).

In sum, looking at both HP and BP results, our findings indicate that smaller countries (except Latvia) as well as larger countries such as the Czech Republic, Hungary, and to some extent Slovakia have a higher level of business cycles synchronisation with the EU-15, especially in the period of crisis at short-run as well as long-run frequencies. On the other hand, in the case of Poland and Latvia, the CWT results indicate that these economies have a very low business cycles synchronisation with the EU-15 group.

\section{CONCLUDING REMARKS}

This paper investigated the magnitude of business cycles synchronisation between 8 CEECs and EU-15 countries based on quarterly data from 1995:Q2 to 2016:Q3. We extracted the business cycles from seasonally adjusted real GDP by applying the HP and BP filters. In order to understand the nature of this particular nexus not only through time aspect, but via frequency dimension as well, our choice of methodology was wavelet coherency and wavelet phase-difference. 
The results revealed that CEECs are generally synchronised with EU-15 business cycles, but the strength of business cycle synchronisation across time and wavelet scales is heterogeneous for all countries' pairs. Wavelet coherence plots calculated with the HP and BP cycles are relatively equable in the majority of the selected countries, which contributes to the robustness of the results. Also, distinct differences exist during the various time-periods, i.e. before, during, and after the WFC (2008-2009) and immediately after it, in ESDC (2010-2011), whereas very strong business cycles synchronisation occurred in almost all CEECs during crisis periods. CWT evidence indicates that CEECs share the same business cycles features when they are in a recession regime, whereas phase arrows suggest that the business cycles of CEECs follow the economic cycle-developments of the EU-15. However, when CEECs are in market boom, we find a few instances that show that some of CEECs begin business cycle conjecture before the EU-15.

Unlike the other large CEECs, we do not find strong business cycles co-movement in the case of Poland and Latvia via HP filter at higher frequencies during the crisis. This finding could indicate that Poland and Latvia have a lower level of business cycles synchronisation, but it also means that their resistance is higher and that Poland and Latvia have a better ability to mitigate external systemic shocks. Taking into account the high extent of resistance to economic shocks that Poland demonstrated in our HP and BP CWT plots, but also the fact that Poland is among pending candidates for European Monetary Union membership, the costs of participation in the monetary union could be substantial in comparison to the benefits. Polish politicians as well as Polish policy-makers are well aware of this, therefore Poland could be a long way off before their adoption of euro.

\section{REFERENCES}

Aguiar-Conraria, L. - Azevedo, N. - Soares, M. J. (2008): Using Wavelets to Decompose the TimeFrequency Effects of Monetary Policy. Physica A: Statistical Mechanics and Its Applications, 387(12): 2863-2878.

Aguiar-Conraria, L. - Soares, M. J. (2011): Business Cycle Synchronization and the Euro: A Wavelet Analysis. Journal of Macroeconomics, 33(3): 477-489.

Allegret, J. P. - Essaadi, E. (2011): Business Cycles Synchronization in East Asian Economy: Evidences from Time-Varying Coherence Study. Economic Modelling, 28(1-2): 351-365.

Artis, M. J. - Fidrmuc, J. - Scharler, J. (2008): The Transmission of Business Cycles: Implications for EMU Enlargement. Economics of Transition, 16(3): 559-582.

Aslanidis, N. (2010): Business Cycle Synchronization between the CEEC and the Euro-Area: Evidence from Threshold Seemingly Unrelated Regressions. Manchester School, 78(6): 538-555.

Baxter, M. - King, R. G. (1999): Measuring Business Cycles: Approximate Band-Pass Filters for Economic Time Series. Review of Economics and Statistics, 81(4): 575-593.

Berdiev, A. N. - Chang, C. P. (2015): Business Cycle Synchronization In Asia-Pacific: New Evidence From Wavelet Analysis. Journal of Asian Economics, 37: 20-33. 
Canova, F. - Ciccarelli, M. - Ortega, E. (2007): Similarities and Convergence in G-7 Cycles. Journal of Monetary Economics, 54(3): 850-878.

Cerqueira, P. A. - Martins, R. (2009): Measuring the Determinants of Business Cycle Synchronization Using a Panel Approach. Economics Letters, 102(2): 106-108.

Chionis, D. - Leon, C. (2009): Synchronization of the Polish and European Business Cycles. Journal of Economic Asymmetries, 6(1): 119-130.

Croux, C. - Forni, M. - Reichlin, L. (2001): A Measure of Comovement for Economic Variables: Theory and Empirics. Review of Economics and Statistics, 83(2): 232-241.

Darvas, Z. - Szàpary, G. (2008): Business Cycle Synchronization in the Enlarged EU. Open Economies Review, 19(1): 1-19.

Degiannakis, S. - Duffy, D. - Filis, G. (2014): Business Cycle Synchronization in EU: A TimeVarying Approach. Scottish Journal of Political Economy, 61(4): 348-370.

De Haan, J. - Inklaar, R. - Jong-A- Pin, R. (2008): Will Business Cycles in the Euro Area Converge? A Critical Survey of Empirical Research. Journal of Economic Surveys, 22(2): 234-273.

Di Giorgio, C. (2016): Business Cycle Synchronization of CEECs with the Euro Area: A Regime Switching Approach. Journal of Common Market Studies, 54(2): 284-300.

Eickmeier, S. - Breitung, J. (2006): How Synchronized Are New EU Member States with the Euro Area? Evidence from a Structural Factor Model. Journal of Comparative Economics, 34(3): 538-563.

Frankel, J. A. - Rose, A. K. (1998): The Endogeneity of the Optimum Currency Area Criteria. Economic Journal, 108(449): 1009-1025.

Fidrmuc, J. - Korhonen, I. (2006): Meta-Analysis of Business Cycle Correlation between the Euro Area and the CEECs. Journal of Comparative Economics, 34(3): 518-537.

Fidrmuc, J. - Korhonen, I. (2010): The Impact of the Global Financial Crisis on Business Cycles in Asian Emerging Economies. Journal of Asian Economics, 21(3): 293-303.

Furceri, D. - Karras, G. (2008): Business-Cycle Synchronization in the EMU. Applied Economics, 40(12): 1491-1501.

Gong, C. - Kim, S. (2013): Economic Integration and Business Cycle Synchronization in Asia. Asian Economic Papers, 12(1): 76-99.

Harding, D. - Pagan, A. (2006): Synchronization of Cycles. Journal of Econometrics, 132(1): 59-79.

Hegerty, S. W. (2010): Central European Business Cycles: Might Global (and Local) Linkages Dominate Regional Ones? Eastern European Economics, 48(2): 56-73.

Herrerias, M. J. - Ordonez, J. (2014): If the United States Sneezes, Does the World Need "PainKillers"? International Review of Economics and Finance, 31: 159-170.

Hodrick, R. - Prescott, E. (1997): Postwar U.S. Business Cycles: An Empirical Investigation. Journal of Money, Credit and Banking, 29(1): 1-16.

Inklaar, R. - Jong-A-Pin, R. - De Haan, J. (2008): Trade and Business Cycle Synchronization in OECD Countries - A Re-Examination. European Economic Review, 52(4): 646-666.

Jiménez-Rodríguez, R. - Morales-Zumaquero, A. - Égert, B. (2013): Business Cycle Synchronization between Euro Area and Central and Eastern European Countries. Review of Development Economics, 17(2): 379-395.

Kutan, A. - Yigit, T. M. (2004): Nominal and Real Stochastic Convergence of Transition Economies. Journal of Comparative Economics, 32(1): 23-36.

Mundell, R. A. (1961): A Theory of Optimum Currency Areas. American Economic Review, 51(4): 657-665.

Obradović, S. - Mihajlović, V. (2013): Synchronization of Business Cycles in the Selected European Countries. Panoeconomicus, 60(6): 759-773. 
Papageorgiou, T. - Michaelides, G. - Milios, J. G. (2010): Business Cycles Synchronization and Clustering in Europe (1960-2009). Journal of Economics and Business, 62(5): 419-470.

Quah, C. H. - Crowley, P. M. (2010): Monetary Integration in East Asia: A Hierarchical Clustering Approach. International Finance, 13(2): 283-309.

Quah, C. H. (2014): Revisiting Business Cycles in the Eurozone: A Fuzzy Clustering and Discriminant Approach. Acta Oeconomica, 64(2): 161-180.

Rahim, A. M. - Masih, M. (2016): Portfolio Diversification Benefits of Islamic Investors with Their Major Trading Partners: Evidence from Malaysia Based on MGARCH-DCC and Wavelet Approaches. Economic Modelling, 54: 425-438.

Rua, A. (2010): Measuring Comovement in the Time-Frequency Space. Journal of Macroeconomics, 32(2): 685-691.

Rua, A. - Nunes, L. C. (2009): International Co-Movement of Stock Market Returns: A Wavelet Analysis. Journal of Empirical Finance, 16(4): 632-639.

Savva, C. S. - Neanidis, K. C. - Osborn, D. R. (2010): Business Cycle Synchronization of the Euro Area with the New and Negotiating Member Countries. International Journal of Finance and Economics, 15(3): 288-306.

Stanisic, N. (2013): Convergence between the Business Cycles of Central and Eastern European Countries and the Euro Area. Baltic Journal of Economics, 13(1): 63-74.

Stock, J. H. - Watson, M. W. (2005): Understanding Changes in Business Cycle Dynamics. Journal of the European Economic Association, 3(5): 968-1006.

Torrence, C. - Webster, P. J. (1999): Interdecadal Changes in the Enso-Monsoon System. Journal of Climate, 12(8): 2679-2690.

Vacha, L. - Barunik, J. (2012): Co-Movement of Energy Commodities Revisited: Evidence from Wavelet Coherence Analysis. Energy Economics, 34(1): 241-247.

Valentinaitè, M. - Snieška, V. (2005): Baltic States Business Cycle Symmetry: Shock Correlation Approach. Engineering Economics, 44(4): 24-30.

Xie, S. - Cheng, T. - Chia, W. (2013): Trade, Finance, Specialization and Synchronization in the Asia-Pacific. Journal of the Asia Pacific Economy, 18(2): 253-270.

Yogo, M. (2008): Measuring Business Cycles: A Wavelet Analysis of Economic Time Series. Economics Letters, 100(2): 208-212. 